\title{
DA CRÍTICA EPISTEMOLÓGICA AO INTERDISCIPLINAR EM PERSPECTIVAS DECOLONIAS E DESCOLONIAIS
}

\author{
FROM THE EPISTEMOLOGICAL CRITICISM TO THE \\ INTERDISCIPLINARY ON DYSFUNCTIONAL AND DECOLONIAL \\ PERSPECTIVES
}

\author{
Kelly Carolyne Cirqueira ALVES ${ }^{1}$ \\ Valéria Lacerda de ALMEIDA ${ }^{2}$
}

\begin{abstract}
RESUMO: Neste artigo, com base em pesquisa bibliográfica apontamos uma reflexão sobre o conhecimento científico e a crítica epistemológica do conhecimento na sociedade contemporânea. A intenção do presente artigo é chamar a atenção para a reflexão de como têm se produzido ciência, evidenciando que é preciso evitar conceber apenas o conhecimento científico enquanto hegemônico. Tal reflexão nos permite problematizar não só o processo de formação do conhecimento e a própria crítica epistemológica, mas também como esse processo conduz a pesquisa interdisciplinar, apontando as perspectivas descolonial e a decolonial como visões críticas que estão surgindo na América Latina enquanto um projeto de desconstrução para a ciência.
\end{abstract}

PALAVRAS-CHAVE: Ciência; Epistemologia; Interdisciplinaridade; Descolonial;

Decolonial.

\begin{abstract}
In this article, based on a bibliographical research, we pointed out a research on a scientific knowledge and an epistemological criticism of knowledge in a contemporary society. The intention of this article is to call attention to a reflection on the science that is produced, evidencing that it is as important as the scientific knowledge as hegemonic. This process allows us to problematize not only the process of the knowledge formation and epistemological criticism itself, but also how the process led to an interdisciplinary research, pointing to the decolonial perspectives such as the critical research that is taking place in Latin America as a deconstruction project to the science.
\end{abstract}

KEYWORDS: Science; Epistemology; Interdisciplinarity; Descolonial; Decolonial.

\footnotetext{
${ }^{1}$ Historiadora, Mestranda em Dinâmicas Territoriais e Sociedade na Amazônia, UNIFESSPA/Campus Universitário de Marabá/PA. kellyalves@unifesspa.edu.br.

2 Engenheira Florestal, Mestranda em Dinâmicas Territoriais e Sociedade na Amazônia, UNIFESSPA/Campus Universitário de Marabá/PA, valeria_florestal@ hotmail.com.
} 


\section{INTRODUÇÃO}

A pesquisa interdisciplinar abre vertentes que permitem a busca de novos referenciais, os quais não privilegiem apenas um saber, mas que proporcionem mapear outras categorias que se formam a partir de outros saberes, entretanto que não sejam consideradas de menor valor no campo científico.

Nesse sentido, refletir o saber científico é pensar sua matriz epistemológica, uma vez que o discurso científico é um discurso precedido de teoria que se difere de outros saberes por possuir conceitos que são esquematizados e estruturados a partir da visão científica. A intenção dessa reflexão é chamar a atenção para a construção de um saber interdisciplinar entre os conhecimentos ditos científicos e os diversos saberes que leve em consideração as múltiplas especificidades de conhecimento.

Perspectivas como as decoloniais e descoloniais, propõem uma desconstrução do conhecimento, fazendo um movimento de valorização de outras fontes e possibilidades de conhecimento pensados a partir de outras categorias, o que levaria a um trabalho interdisciplinar, dialogando com diversos saberes e a perspectiva científica. Assim, a prática interdisciplinar surge como uma superação a um conhecimento compartimentado, moderno e eurocentrado que não veem em outras vertentes possibilidades de conhecimento por buscarem uma veracidade na ciência, quando a própria noção de verdade é questionável, por serem carregada de poder.

Logo, o trabalho interdisciplinar na pesquisa científica é de fundamental importância para explorar as fronteiras entres as disciplinas, para dialogar com outras teorias, ampliando o próprio conhecimento disciplinar. O interdisciplinar a partir do diálogo permite a construção de novos saberes que podem contribuir efetivamente para a realidade, e quando falamos em diálogo a partir do interdisciplinar estamos pensando em interação e trocas de ambas as partes, proporcionando avanços na construção do conhecimento.

Em resumo proponho considerar, a partir de uma reflexão epistemológica, as perspectivas decolonial e descoloniais como propostas interdisciplinares por abarcarem estudos dos mais variados tipos de conhecimento, rompendo com os modos de produção do conhecimento e criticando a ciência enquanto um espaço agregador de experiências coloniais que manteria o discurso de um conhecimento moderno que não leva em consideração as múltiplas especificidades e pluralidades de se fazer ciência. 
Perspectivas descoloniais e decoloniais como essas, defendem uma ruptura epistemológica que propõem pensar na América Latina a partir da própria América Latina, buscando construir referenciais que valorizem a perspectiva subalternizada.

A análise se ancora, a partir do conceito de epistemologia, nas ciências e na proposta interdisciplinar, mobilizando autores como Hilton Japiassu (1934) com reflexões acerca da interdisciplinaridade e da epistemologia. José Jeremias de Oliveira Filho (1976) que propõe uma reconstrução teórica e metodológica para as ciências sociais, Augusta Thereza de Alvarenga (2011) discutindo a interdisciplinaridade. Michel Foucault (2005) para pensar os sentidos da verdade no conhecimento e Thomas Kuhn (2013) com os paradigmas que são construídos na ciência. Além da apropriação das ideias de outros autores como Boaventura de Sousa Santos (2010), Walter Mignolo (2008) e Aníbal Quijano (2005) com as propostas decoloniais e descoloniais que vem se construindo em contraponto aos processos resultantes da colonização no conhecimento; autores esses que em certa medida podem ser trabalhados a partir da proposta interdisciplinar, uma vez que essas abordagens apontam debates no campo da cultura, da política e da ciência.

\section{REFLEXÃO EPISTEMOLÓGICA: BREVES APONTAMENTOS}

Interessa a essa sessão, a abordagem de estudos feitos por Japiassu ao apresentar a importância da reflexão epistemológica para o trabalho científico, e situa-lo quanto ao conceito de epistemologia: "essencialmente, a epistemologia é o estudo crítico dos princípios, das hipóteses e dos resultados das diversas ciências. Semelhante estudo tem por objetivo determinar a origem lógica (não psicológica) das ciências, seu valor e seu alcance objetivos" (1934, p. 25).

A epistemologia ainda de acordo com Japiassu (1934) é uma atitude reflexiva sobre o método científico, de como fala o cientista, de como é construído o saber científico, de como é legitimado esse saber e ainda mais, de como seria possível o conhecimento e o que de fato é o conhecimento. A epistemologia, nesse sentido, bebe, de certa maneira, na filosofia, se colocando a serviço de compreender e de fazer a pergunta de como é possível atingir o conhecimento. 
Tradicionalmente, a epistemologia é considerada como uma disciplina especial no interior da filosofia. Eram os filósofos que faziam as pesquisas em epistemologia. Esta era "para" a ciência ou "sobre" a ciência, mas não era obra dos próprios cientistas. Todas as filosofias desenvolveram espontaneamente uma teoria do conhecimento e uma filosofia das ciências tendo por objetivo evidenciar os meios do conhecimento científico, elucidar os objetos aos quais tal conhecimento se aplica, ou fundar a validade deste conhecimento. Como se pode notar, este programa visa a um duplo fim: em primeiro lugar, descobrir um conhecimento positivo: de que fala o cientista? Como fala dele? Em segundo lugar, visa a ultrapassar os limites dessas questões, fazendo da prática científica o objeto de um juízo: o que é uma verdade científica? Em que condições há verdade? Em que limites podemos falar de verdade científica? (1934, p. 25).

A filosofia de acordo com Japiassu estabelece limites no conhecimento científico, uma vez que a ciência não explica tudo.

Tal limitação se exprime numa série de oposições: ciência e sabedoria, conhecer e pensar, compreender e conhecer, etc. Estas duas atividades, de distinção e de limitação, supõem o uso de uma categoria, que é o produto da intervenção filosófica. 3. Buscar a natureza da ciência. Ora, a ciência não existe. Do ponto de vista da prática dos cientistas, não há ciência em geral, mas sistemas de conhecimentos específicos, em evolução e apropriados a seus objetos. "A" ciência não passa de uma ficção. (1934, p. 26).

Aqui se encontra o ponto crucial da nossa discussão, de pensar a ciência não enquanto um acúmulo de informações, temas, métodos e conceitos, mas enquanto um instrumento que se constrói historicamente e possui uma função social - ou não - de explicar algo, indo mais além, se deve fazer o exercício de compreender a ciência como interpretação/leitura de mundo para a compreensão do objeto. A ciência ainda desenvolve a função de dominar por meio das classificações o conhecimento, habitualmente tende a classificar, invalidar e silenciar o que não considera enquanto saber científico, ou seja, possui modelos de classificação.

Nesse momento de nossa reflexão vale destacar Foucault (2005) que pensa a verdade no conhecimento científico a partir das relações de poder e como se formam sujeitos a partir dessas relações.

Meu objetivo será mostrar-lhes como as práticas sociais podem chegar a engendrar domínios de saber que não somente fazem aparecer novos objetos, novos conceitos, novas técnicas, mas também fazem nascer novas formas totalmente novas de sujeitos e de sujeitos de conhecimento (2005, p. 07). 
Em outros termos, trata-se de compreender que toda relação de poder se estabelece pelo saber, que irá justificá-lo de alguma forma. Desde logo, cabe enfatizar que para Foucault o homem é resultado de um determinado corpo de conhecimento que se forma para exercer poder e controle.

\begin{abstract}
Assim, gostaria particularmente de mostrar como se pôde formar, no século XIX, um certo saber do homem, da individualidade, do indivíduo normal ou anormal, dentro ou fora da regra, saber este que, na verdade, nasce das práticas sociais, das práticas sociais do controle e da vigilância. E como, de certa maneira, esse saber não se impôs a um sujeito de conhecimento, não se propôs a ele, nem se imprimiu nele, mas fez nascer um tipo absolutamente novo de sujeito de conhecimento (FOUCAULT, 2005, p. 8).
\end{abstract}

Em decorrência dessas constatações, Foucault propõe compreender as relações de luta e de poder para apreender o conhecimento, pois este se forma a partir de regras e jogos não definidos e "[...] parecem uma das formas pelas quais nossa sociedade definiu tipos de subjetividade, formas de saber, e, por conseguinte, relações entre homem e verdade que merecem ser estudadas" (2005, p. 11). As reflexões de Foucault nos auxiliam a pensar no lugar de fala que os sujeitos ocupam, seu status e a sua posição que ajudam a regulamentar e legitimar a linguagem.

Foucault prefere olhar a dispersão do discurso científico, porque um discurso aparece em dada época e outra não? Porque em um dado momento histórico o discurso é validado, sofre dispersão, silenciamento e apagamentos? Esses questionamentos são pertinentes para se pensar as modificações do discurso, os quais se alteram de acordo com as demandas das instituições, sendo preciso postular que cada discurso tem suas regras de possibilidade e uma estratégia de se constituir linguisticamente, teoricamente e metodologicamente dependendo das condições de produção.

Para Foucault, "pareceu [...] que, enquanto o sujeito humano é colocado em relações de produção e significação, é igualmente colocado em relação de poder muito complexas" (1995, p.232). Foucault entende as relações de poder a partir das resistências, uma vez que onde há poder, há também resistências, há jogos e disputas semânticas pelo sentido.

Nesse sentido, a crítica epistemológica assume um papel importante na construção do conhecimento, apontando a necessidade de pensar o conhecimento a 
partir do diálogo e não como uma imposição de verdades inquestionáveis e sedimentadas. A pesquisa interdisciplinar surge então com esse desafio de repensar uma nova postura para se fazer ciência.

\section{O TRABALHO INTERDISCIPLINAR}

Cada ciência possui sua área disciplinar fundada a partir de suas epistemologias, que possuem seus próprios métodos e perspectivas. O problema é quando a área disciplinar se torna uma "jaula" apresentando apenas uma perspectiva para trabalhar o conhecimento. Nesse sentido, não se deve considerar a ciência uma caixinha que não possa dialogar com outras áreas disciplinares.

A respeito da interdisciplinaridade Japiassu, considerava que ela ainda estava em processo de formação não apenas como um conceito, mas como uma prática, que vem responder à necessidade de repensar a ciência e as novas disciplinas que estão surgindo.

\footnotetext{
Evidentemente, a metodologia interdisciplinar irá exigir de nós uma reflexão mais profunda e mais inovadora sobre o próprio conceito de ciência e de filosofia, obrigando-nos a desinstalar-nos de nossas posições acadêmicas tradicionais, das situações adquiridas, e a abrir-nos para perspectivas e caminhos novos. Ademais, exigirá de nós que reformulemos nossas estruturas mentais, que desaprendamos muita coisa que desconfiemos das cabeças bem "arrumadas", pois, em geral, são bastante "desarrumadas", tendo necessidade de nova "rearrumação". (1976, p. 42)
}

O trabalho interdisciplinar vem surgindo como contraponto ao conhecimento cada vez mais compartimentado e dividido, vem se construindo como um diálogo entre as disciplinas propondo rever os métodos, estruturas e mecanismos. A necessidade da interdisciplinaridade na produção do conhecimento mostra a necessidade de superação dessa visão fragmentada dos processos de produção do conhecimento recuperando seu caráter de integração entre os diversos saberes. Esse diálogo interdisciplinar aproxima os saberes, oriundos dos diversos campos do conhecimento, auxiliando uma maior compreensão epistemológica acerca dos mais diversos objetos de estudo. Conforme saliente, Alfredo Wagner “A diversidade identitária está impondo releituras e revisões de abordagens que se cristalizaram nos meandros do campo da produção intelectual e científica" (2008, p. 76). 
Construiu-se uma visão unitária do conhecimento que o colocou enquanto universal $^{2}$, para Japiassu a prática interdisciplinar não se reduz a uma questão de "modismo", mas enquanto uma nova etapa de construção do conhecimento que não se pretende ter um caráter universalizante, uma vez que a ciência pode adotar outros métodos para integrar a pesquisa "[...] a interdisciplinaridade reivindica as características de uma categoria científica, dizendo respeito à pesquisa” (JAPIASSU, 1976, p. 51).

Japiassu, nos convida a pensar a interdisciplinaridade como uma prática que vem se apresentando como uma "anticiência" ou como uma oposição sistemática à forma tradicional de organização do saber, que cada vez mais se divide em grades e áreas disciplinares sem que haja abertura para o diálogo interdisciplinar. A interdisciplinaridade nesse sentido trabalha no "entre-lugar"3 das áreas disciplinares. Em certa medida, o autor nos apresenta uma crítica ao fato das disciplinas estarem cada vez mais fechadas e compartimentadas.

\begin{abstract}
Elas se separam umas das outras por compartimentos estanques, por fronteiras rígidas, cada disciplina convertendo-se num pequeno feudo intelectual, cujo proprietário está vigilante contra toda intromissão em seu terreno cercado e metodologicamente protegido contra os "inimigos" de fora. E não somente entre as disciplinas, mas até mesmo no interior dos domínios de estudo, existem cisões metodológicas rígidas, que frequentemente tornam impossível a compreensão recíproca dos especialistas e sua eventual colaboração (1976, p. 58).
\end{abstract}

Em vista do fato apresentado, o trabalho interdisciplinar na pesquisa é de fundamental importância para explorar as fronteiras entres as disciplinas, para dialogar com outras teorias ampliando o próprio conhecimento disciplinar. O interdisciplinar, a partir do diálogo, permite a construção de novos saberes que podem contribuir efetivamente para a realidade. Por outro lado, a obra de Japiassu nos proporciona um exercício de reflexão para justificar a escolha e quais os objetivos do trabalho interdisciplinar na pesquisa.

Outro objetivo a que se propõe o interdisciplinar consiste em desenvolver a preocupação de melhor guiar a pesquisa propriamente dita. Em outros

\footnotetext{
${ }^{2}$ Estabelece-se uma hegemonia sobre o conhecimento, considerando que há um único conhecimento válido e verdadeiro.

${ }^{3}$ Em nossas reflexões consideramos o conceito de "entre-lugar" a partir das abordagens de Homi Babba que propõem pensar o conhecimento e a cultura a partir de um ambiente fronteiriço onde os sujeitos constroem saberes e identidades.
} 
termos, o que se tem em vista é a descoberta de melhores métodos para planejar e guiar a ação, isto é, para fornecer informações novas, indicar diversos modos de atingir um objetivo, esclarecer os resultados de uma política, em suma, ampliar as perspectivas daquelas que pretendem agir ou resolver problemas sociais concretos ou tomar decisões racionais (JAPIASSU, 1976, p. 55).

A partir de então, a pesquisa científica passaria a incorporar meios e outros caminhos para a construção do conhecimento a partir de conceitos não apenas científicos e ditados por cada disciplina, mas fazendo do diálogo interdisciplinar um método para compreensão do objeto a ser estudado, como um "melhor guia". A busca por uma desconstrução do conhecimento científico parece começar a partir do diálogo interdisciplinar como um dos aspectos fundamentais, por se dispor a repensar as metodologias e teorias que vem sendo empregadas nas pesquisas científicas.

Por outro lado, Japiassu acrescenta que para compreender o sentido do interdisciplinar deve haver o domínio disciplinar, ou seja, ter compreensão e domínio teórico, metodológico e material da disciplina científica à qual está filiado. Uma vez que cada disciplina estabelece e define suas fronteiras, são exatamente essas fronteiras que determinam os seus objetos de pesquisa, seus métodos, conceitos e teorias. Esse domínio da disciplina permite saber os limites da realização do trabalho interdisciplinar para que não haja apenas uma "montagem" de vários conceitos e métodos sem estarem conectados. É fazer o diálogo interdisciplinar sem esquecer a sua matriz epistemológica, estabelecendo um elo entre os campos.

No que diz respeito a essa reflexão, ainda na visão do autor:

Ora, não se trata de negar certas recorrências nas disciplinas científicas, mas
de mostrar que não é mais possível conceber a ciência como um monumento
que se construiria estágio por estágio, cumulativa e continuamente, sobre
fundamentos definitivamente sólidos e garantidos. O que importa conhecer e
enfatizar é que, ao lado das recorrências, torna-se cada vez mais urgente uma
análise das concorrências disciplinares, vale dizer, das colaborações e
intercâmbios recíprocos, numa palavra, dos concursos interdisciplinares
(JAPIASSU, 1976, p. 63).

Portanto a interdisciplinaridade está surgindo como uma possibilidade de abertura para a elaboração de outros conhecimentos que se ancoram em outras perspectivas e que trazem à tona a crítica do conhecimento enquanto algo pronto, acabado, positivo e verdadeiro. Assim, a própria "veracidade" do conhecimento 
científico estabelece uma problemática, uma vez, que cada conhecimento elabora para si as suas verdades que contribuem para a manutenção das relações de poder, conforme Foucault.

A ideia do diálogo interdisciplinar na pesquisa nos anuncia um enriquecimento em sentido mútuo, já que nesse processo se desconstrói, ou pelo menos se pretende, a ideia absolutizada e universalizada do que seja o conhecimento. $\mathrm{O}$ interdisciplinar permite pensar o conhecimento enquanto um processo dinâmico e complexo resultante das relações sociais.

A socióloga Augusta Thereza Alvarenga retoma os argumentos de Japiassu ao apontar os fundamentos filosóficos e teórico-metodológicos da interdisciplinaridade. De acordo com a autora a discussão acerca da interdisciplinaridade se inscreve em um momento de reflexão crítica sobre o avanço da ciência, da tecnologia e do conhecimento gerado pela ciência moderna. Nesse sentido, [...] se caracteriza basicamente por um modelo de pensamento simplificador, pois é fundado em racionalidade considerada estreita pelas implicações que gera e pelo funcionamento que opera nos processos do conhecimento disciplinar (2011, p. 4).

Segundo Alvarenga, a ciência moderna vem concebendo um modelo hegemônico de ciência que considera apenas duas formas de conhecimento científico, as disciplinas formais da lógica e matemáticas e as ciências empíricas. A autora sugere pensar a partir do trabalho interdisciplinar o modo como tem sido construída a ciência, pensando na reflexão crítica desses saberes e do seu real significado para a sociedade contemporânea.

\footnotetext{
Esse modelo, fundado em determinados princípios, passa a caracterizar, por um lado, o que se conhece como paradigma hegemônico, que preside a ciência moderna. Por outro, a crítica aos limites de seus princípios passa a se apresentar como indicadora da importância e dos desafios para o reconhecimento da interdisciplinaridade como forma alternativa de produzir conhecimento científico, diante da complexidade do mundo contemporâneo. Não se trata, pois, de superação do conhecimento disciplinar sob o qual se funda tal modelo, mas de reconhecer a pertinência e a relevância de outro modo de fazer ciência, de gerar conhecimento, sobretudo porque a realidade nem sempre pode ser enquadrada dentro do universo do domínio disciplinar (2011, p. 11).
}

Acerca dos paradigmas da ciência moderna à qual Alvarenga cita, a autora faz referência ao filósofo Thomas Kuhn em A estrutura das revoluções científicas. 
Segundo Kuhn (2013, p. 13) “[...] considero 'paradigmas’ as realizações científicas universalmente reconhecidas, que durante algum tempo, fornecem problemas e soluções modelares para uma comunidade de praticantes de uma ciência". Com isso, é possível compreender, com base nas colocações de Alvarenga e a partir do conceito de paradigmas, que há um paradigma hegemônico da ciência moderna que estabelece uma ruptura com os saberes que a precedem, pois se fecha em um modelo global do que seja o conhecimento científico e "[...] excluí outras formas de conhecimento que não o positivista [...]" (2011, p. 55).

A interdisciplinaridade para a autora não representa uma superação do conhecimento científico, mas uma alternativa inovadora na produção do conhecimento e na prática da pesquisa científica. Ou seja, a interdisciplinaridade vem sendo precursora na crítica e "na busca de respostas aos limites do conhecimento simplificador, dicotômico e disciplinar da ciência moderna ou clássica" (ALVARENGA, 2011, p. 55).

Além disso, a autora afirma que a interdisciplinaridade não se apresenta apenas como uma alternativa, mas enquanto uma alternativa que seja complementar, uma vez que ela busca relacionar os mais diversos saberes, propondo diálogo no campo teórico, filosófico, práticos e científicos.

Desse ponto de vista, portanto:

Como campo em construção, os desafios se ampliam, uma vez que a partir dessas reflexões podemos inferir que as trocas disciplinares para o trabalho interdisciplinar implicam ultrapassar as fronteiras não somente das próprias disciplinas científicas, mas igualmente das filosóficas (2011, p.55).

O que podemos observar das questões até agora apresentadas, é como a proposta interdisciplinar vem sendo construída a partir de novos desafios, o que implica pensar no interdisciplinar não apenas enquanto um novo modo de produzir conhecimento, mas também como uma proposta que busque novos instrumentos teóricos e metodológicos para a investigação social. Nesse seguimento Alvarenga aponta algumas afirmações de Oliveira Filho (1976) a partir de seu artigo Reconstruções metodológicos de processos de investigação social, no qual o autor sugere que sejam revisados os modelos teóricos e metodológicos das ciências sociais. Como pode ser observado na seguinte passagem retomada por Alvarenga: 
Para uma primeira resposta a esse tipo de indagação, o recurso ao esquema de classificação proposto por Oliveira Filho (1976), que tem como objetivo diferenciar o trabalho do filósofo da ciência do trabalho do cientista, apresenta-se como estratégia heurística. Isso porque esse esquema propõe-se a representar o que o autor entende por 'reconstruções metodológicas de processo de investigação social, tendo em vista, no caso, o trabalho do filósofo da ciência que se debruça sobre determinados discursos de cientistas, buscando identificar os instrumentais metateóricos que fundamentam suas propostas investigativas no campo da ciência dos pontos de vista ontológico, lógico e epistemológico' (2011, p. 53).

O foco da crítica de Oliveira Filho é que com o desenvolvimento tecnológico da pesquisa social é preciso que haja "[...] a investigação reorientadora dos princípios, hipóteses, e objetivos a partir da análise dos fundamentos lógicos, epistemológicos e ontológicos de teorias e técnicas" (1976, p. 264). Ainda na visão de Oliveira filho:

\begin{abstract}
A função reorientadora da metodologia teórica permitirá importantes intervenções na atividade científica das ciências sociais. A metodologia não pode ser um luxo intelectual de cientistas diletantes ou de filósofos cientificamente ilustrados. Ao assinalar o seu valor "instrumental", enquanto determinado nível de prática, a que uma reflexão metodológica pretende fundar, salientou-se a importância de tornar explícitas as justificações e críticas em torno das decisões que fazem os cientistas sociais entre técnicas, teorias e metateorias alternativas. Resta saber se as visões alternativas da caminhada e o caminhar não se impedem, conquanto se diferenciem (1976, p. 276).
\end{abstract}

De acordo com Alvarenga, a estratégia metodológica que Oliveira Filho propõe para as ciências sociais, permite visualizar e pensar nas "possibilidades que se reveste a pesquisa interdisciplinar", uma vez que possibilita ao cientista social uma série de escolhas "hipóteses, conceitos e teorias, ou entre métodos e técnicas alternativos de pesquisa" (1976, p. 276) conduzindo ao trabalho interdisciplinar. Tanto Alvarenga, quanto Oliveira Filho vão destacar a necessidade de romper as barreiras entre as disciplinas, no entanto a autora destaca que as barreiras sejam rompidas também no campo filosófico. Portanto, é importante um olhar mais cuidadoso e crítico para o objeto que está sendo analisado.

Nesse sentido, saber colocar problemas relevantes e pertinentes no âmbito da pesquisa científica - ou seja, identificar se tais problemas são mais propriamente de natureza científica ou filosófica - é o primeiro passo para enfrentar problemas ou desafios teóricos-metodológicos no campo da ciência (2011, p. 60). 
Tais considerações evidenciam que o conhecimento da ciência deve ser sempre perguntado, ou seja, deve-se fazer a pergunta certa para o objeto. Na visão da autora, fazer a pergunta certa ao objeto implica na escolha das estratégias e métodos de investigação para trabalhar os problemas que a pesquisa irá colocar, para ela esse processo permite saber "em que nível as trocas disciplinares poderão ser realizadas e o nível que nossa investigação pode abarcar" (2011, p. 60).

Apesar da interdisciplinaridade ser uma proposta em construção que vem apresentado muitos sentidos e desafios, ela tem mostrado que o interdisciplinar permite o movimento de leitura - diríamos até mais sensível - de práticas e valores das relações sociais e de sujeitos que antes não eram trabalhados pela ciência. O interdisciplinar, a partir das colocações dos autores, nos mostra que não se trata apenas de um movimento de diálogo entre as fronteiras disciplinares ou até mesmo de rompimento dessas fronteiras, mas implica também na crítica epistemológica de como a ciência vem sendo construída.

Nesse terceiro momento do texto, apontamos algumas perspectivas que estão surgindo na América Latina, em contrapartida à forma como o conhecimento é trabalhado hegemonicamente, e propondo outros conceitos, hipóteses e visões que se olhadas nesses processos de formação do conhecimento estariam, em certa medida, em uma perspectiva do interdisciplinar.

\section{PERSPECTIVAS CRÍTICAS AO CONHECIMENTO CIENTÍFICO MODERNO NA AMÉRICA LATINA}

Autores como Aníbal Quijano, Boaventura de Sousa Santos ${ }^{4}$ e Walter Mignolo nos permitem pensar a partir da perspectiva subalterna e perceber quem está estabelecendo uma crítica à maneira como o conhecimento científico vem sendo trabalhado, sugerindo um compromisso ético-político em elaborar um conhecimento contrahegemônico, que rompa com o projeto colonizador. Essa postura seria uma

\footnotetext{
${ }^{4}$ Boaventura de Sousa Santos é formado em Direito, mas é membro do grupo latino-americano Colonialidade/Modernidade e suas contribuições ao grupo são de extrema relevância para as áreas das ciências sociais, apontamos aqui o pensamento de Santos tomando como base seus estudos em torno das epistemologias, uma vez que o autor aponta as formas de exclusão e silenciamentos de povos e culturas subalternos por meio das epistemologias dominantes e universalizantes.
} 
resposta de luta que enfrenta a colonialidade do poder ${ }^{5}$. A partir dessas perspectivas subalternas se faz um movimento de crítica ao conhecimento dito científico que, na visão dos autores, é colonial, moderno e eurocentrado. Os autores propõem pensar a modernidade como um processo vinculado à experiência colonial.

Quijano (2005) questiona o processo de dominação a partir das classificações de raças enquanto superiores e inferiores, e sustenta que essa ideia foi assumida pelos conquistadores com a principal justificativa das relações de dominação, ou seja, passouse a classificar a população nesse novo padrão de poder, onde categorias como índio, negro e mestiço passaram a indicar sujeitos que serão historicamente explorados, subjugados, dominados e marginalizados, sempre colocados enquanto raça inferior.

Quijano (2005) vai destacar em sua crítica, como esses processos de dominação ainda estão presentes na nossa história e nas próprias relações sociais e como essas classificações fundamentam as relações capitalistas e são reproduzidas por esses mecanismos do sistema mundo-capitalista ${ }^{6}$. De acordo com Quijano (2005, p. 122) o notável disso tudo não é o fato de o colonizador ter imaginado a si próprio enquanto "branco" e superior, e aos outros enquanto inferiores, devendo ser salvos de sua própria ignorância. O notável e mais problemático de todo esse processo é o fato de o colonizador ter sido capaz de difundir e estabelecer essa perspectiva histórica como hegemônica, o que Quijano vai chamar de colonialidade do poder. Em outras palavras, a colonialidade do poder seria uma matriz de poder fundamentada na experiência colonial que garante sua continuidade de dominação.

Boaventura de Souza Santos nomeia o pensamento moderno enquanto abissal. O pensamento abissal consiste em um sistema de distinção visíveis e invisíveis que dividem a realidade social em dois universos.

Refiro-me aos conhecimentos populares, leigos, plebeus, camponeses, ou indígenas do outro lado da linha. Eles desaparecem como reconhecimento relevante ou comensurável por se encontrarem para além do universo do verdadeiro e do falso. É inimaginável aplicar-lhes não só a distinção

\footnotetext{
${ }^{5}$ Conceito utilizado por Quijano para se referir ao processo de formação das relações sociais após o processo de colonização da América.

${ }^{6}$ Conceito formulado por Immanuel Wallerstein em que o autor aponta a formulação e a divisão do sistema-mundo desde o feudalismo até o sistema capitalista, "um sistema mundo é um sistema social, um sistema que possui limites, estruturas, grupos associados, regras de legitimação e coerência. A sua vida é feita das forças em conflito que o mantém unido por tensão e o dilaceram na medida em que cada um dos grupos procura eternamente remodela-lo a seu proveito. Tem as características de um organismo, na medida que tem um tempo de vida durante o qual suas características mudam em alguns aspectos e permanecem estáveis noutros (Wallerstein, 1974a, p. 337). Ver em “O sistema mundial moderno" (1974)
} 
científica entre verdadeiro e falso, mas também as verdades inverificáveis da filosofia e da teologia que constituem o outro conhecimento aceitável deste lado da linha. Do outro lado da linha, não há conhecimento real, existem crenças, opiniões, magia, idolatria, entendimentos intuitivos ou subjetivos, que na melhor das hipóteses, podem tornar-se objetos ou matéria-prima para a inquirição científica (2010, p. 25).

Nessa perspectiva, a consciência e o conhecimento subalterno são silenciados pelo discurso colonial e moderno, onde tudo que não pode ser pensando nos parâmetros de verdadeiro ou falso, legal ou ilegal ocorre na zona colonial. Trata-se, portanto, da manutenção de uma colonialidade do saber ${ }^{7}$, isso implica dizer que mesmo com o fim do colonialismo ${ }^{8}$ a lógica colonial se transfere para o campo do conhecimento e das ciências mantendo a hegemonia eurocêntrica como uma perspectiva universal e superior, privilegiando o ponto de vista do colonizador e silenciando as narrativas das populações subalternizadas.

Portanto, o que Boaventura aponta é como esse sistema de classificação das populações provocou também um processo de esquecimento e apagamento de outras formas de conhecimento. Boaventura nos convida a pensar na opção decolonial ${ }^{9}$ enquanto um processo de "aprender a desaprender", valorizando a diversidade epistemológica do mundo e o reconhecimento da existência de uma pluralidade de formas de reconhecimento além do científico" (SANTOS, p. 25, 2010).

Nesse sentido, seria elaborar um conhecimento contra-epistemológico, ao qual Boaventura (2010) designa como ecologia de saberes, sendo ecologia porque se baseia exatamente no reconhecimento da pluralidade de conhecimento, assentado na ideia de que é preciso uma reavaliação nessa distinção ente os conhecimentos. Elaborar um conhecimento contra-epistemológico nos levaria a um saber emancipatório que nos permite reconhecer a heterogeneidade de saberes, promovendo trocas e interações entre a ciência e os saberes tradicionais, conforme salienta Boaventura "Trata-se, por um lado, de explorar a pluralidade interna da ciência, isto é, as práticas científicas alternativas que têm se tornado visíveis por meio das epistemologias” (2010, p. 88).

\footnotetext{
${ }^{7}$ Colonialidade do Saber, conceito discutido por Walter Mignolo.

${ }^{8}$ Política em que se exerce controle sobre o outro, no entanto colonialismo se difere do conceito de colonialidade pois a colonialidade procura explicar a modernidade vinculada ao processo colonial, explicitando que ainda se mantém as formas de dominação colonial por meio das classificações das populações a partir de categorias como raça e gênero.

${ }^{9}$ Perspectiva que faz crítica aos processos que considera resultantes da colonização e que denuncia como a dominação do colonizador ainda persiste.
} 
$\mathrm{Na}$ perspectiva decolonial se procura a superação da experiência colonial construindo um projeto político que seja pautado não na modernidade, mas nas epistemologias do $\mathrm{Sul}^{10}$, ou seja, pensar na América Latina a partir da própria América ${ }^{11}$. No entanto, como trabalhar esses "conceitos tradicionais/saberes do Sul" como ciência, sem negar os saberes modernos já impostos?

Walter Mignolo (2008) nos ajuda a resolver essa questão a partir do conceito de desobediência epistêmica, que seria uma estratégia descolonial ${ }^{12}$ baseada na mediação dos conhecimentos para questionar o pensamento ocidental enquanto hegemônico, isto é, não se trata de deslegitimar ou abandonar o pensamento ocidental, mas de pensar a partir das línguas e categorias de pensamentos não incluídos nos fundamentos do pensamento ocidental. É pensar na construção do conhecimento enquanto limites, fazendo a reflexão na construção e subversão dos sentidos que se construíram após a experiência colonial.

O projeto descolonial segundo Mignolo (2008) consiste em uma crítica política, apontando o reconhecimento do pensamento ocidental moderno, mas o trabalha no "entre-lugar", como um espaço onde se rompe os binarismos, onde se percebe os limites das ideias pré-estabelecidas e fixas. Mas o que deve ser destacado é que tanto as opções decolonial quanto a descolonial fazem críticas aos conceitos próprios da modernidade. Catherine Walsh (2010) propõem pensar essas propostas como projetos políticossociais-epistêmicos-éticos que procuram enfrentar a matriz colonial de poder, questionando as ausências de saberes tempos e diferenças, onde se tornam visíveis as maneiras de ser, viver e saber. Para Walsh (2010) a duas propostas demonstram a necessidade de mudar não só as relações, mas também as estruturas, condições e dispositivos de poder que mantém as desigualdades. No entanto, Walsh pontua uma diferença entre as duas propostas, segundo ela:

Suprimir o "s" e nomear descolonial ou de-colonial não é promover um anglicismo. Pelo contrário, é marcar uma distinção com o significado em castelhano do "des". Não pretendemos simplesmente desarmar, desfazer ou

\footnotetext{
${ }^{10}$ Conceito designado por Boaventura como um conjunto de intervenções epistemológicas que apresenta uma proposta de valorização dos conhecimentos do Sul.

${ }^{11}$ E não apenas na própria América Latina, atualmente os diversos autores tanto latino-americanos, indianos, africanos, etc. questionam o universalismo do conhecimento e propõem uma releitura da colonização. Nesse sentido, tanto o decolonial quanto o descolonial se assemelham as teorias póscoloniais, mas como ponto de partida usam a América Latina.

${ }^{12}$ Perspectiva que propõe a construção de um projeto político que não seja pautado nos conceitos da modernidade.
} 
reverter o colonial, ou seja, passar de um momento colonial a outro nãocolonial, como se fosse possível que os padrões e suas pegadas desistam de existir. A intenção, portanto, é sublinhar e provocar um posicionamento uma postura e atitude contínua - de transgredir, intervenir, in-surgir e incidir. O de-colonial denota, então, um caminho de luta contínuo no qual podemos identificar, visibilizar e alentar "lugares" de exterioridade e construções alternativas. (WALSH, 2010, p. 13)

Nesse sentido, ambas as propostas podem ser vistas como processos de resistências que evidenciam outras formas de pensar o conhecimento e as relações sociais, propondo um diálogo e resgate de outras formas de saberes, a exemplo de saberes indígenas, de comunidades tradicionais, movimentos sociais, etc. Para Walsh é "um trabalho que procura desafiar e derrubar as estruturas sociais, políticas e epistêmicas da colonialidade, e alentar novos processos, práticas e estratégias de intervenção para criticamente ler o mundo" (WALSH, 2010, p. 12). O que o referido autor sugere é "pensar não só "a partir" das lutas dos povos historicamente subalternizados, mas também "com" sujeitos, conhecimentos e modos distintos de estar, ser e viver" (2010, p. 13).

Diante disso, é necessário pensar como esses processos de decolonização se reconfiguram e constroem processos de resistências que vão servir como instrumentos políticos para a veiculação de uma memória dos referidos grupos. Depois de feito esse movimento de desconstrução do conhecimento é que podemos começar a pensar na construção de um conhecimento pluralista, analisando outras formas de produzir sentidos.

Portanto, tais perspectivas são consideradas como teorias em construção, havendo uma larga história e uma genealogia de intervenções e conceitos sobre o decolonial ou descolonial que se apresentam em um processo de luta contínua e de embates políticos reproduzidos principalmente no campo científico.

\section{CONSIDERAÇÕES FINAIS}

Em primeiro lugar as perspectivas dos autores auxiliam na reflexão não só do processo de formação do conhecimento e da crítica epistemológica, mas também como esse processo conduz a pesquisa interdisciplinar. Nesse sentido, o trabalho interdisciplinar feito à luz de perspectivas que propõem outras vertentes de valorização do conhecimento possibilitam um movimento de desconstrução dessa visão 
fragmentada do conhecimento; visão essa que trata da história de apagamentos e silenciamentos de outras formas de conhecimento, saberes que acabam não sendo reconhecidos valorizados ou ignorados.

Ao longo do texto, enfatizamos o poder hegemônico que se estabeleceu sobre o conhecimento. No entanto, a partir das perspectivas decolonial e descolonial se institui um movimento de contestação dos valores que são frutos da modernidade e que expressam as narrativas coloniais contadas a partir do colonizador. Ambas as perspectivas apresentam um projeto emancipatório do conhecimento através da valorização dos saberes tradicionais em diálogo com os sujeitos.

O projeto colonizador luta para estruturar e impor conceitos e manter a sua hegemonia através do conhecimento, enquanto um instrumento de dominação e reprodução de desigualdades. Ou seja, o projeto colonizador do conhecimento é pautado no imaginário dominante que está presente nos discursos coloniais apresentando a civilização moderna como a mais desenvolvida e superior.

Essa imposição é conseguida através do estabelecimento de normas e ideologias e esse processo violento de imposição se dá essencialmente e fundamentalmente por meio da linguagem na disputa de sentidos de palavras e conceitos. A valorização de um saber interdisciplinar que dialogue com mais diversos sujeitos é de extrema importância para se romper as relações dominantes que se manifestam sobre o contexto histórico das relações sociais.

\section{REFERÊNCIAS BIBLIOGRÁFICAS}

ALMEIDA, A. W. B. Antropologia dos archivos da Amazônia. Rio de Janeiro: Casa 8 / Fundação Universidade do Amazonas, 2008, p. 15-153.

ALVARENGA, Augusta Thereza de; PHILIPPI JÚNIOR, Arlindo; SOMMERMAN, Américo; ALVARES, Aparecida Magali de Souza; FERNANDES, Valdir. Histórico, fundamentos filosóficos e teórico-metodológicos da interdisciplinaridade. In: PHILIPPI Jr, A.; NETO, A. J. S. Interdisciplinaridade em ciência, tecnologia \& inovação, Barueri-SP, Manole, 2011, páginas 3 a 68

FOUCAULT, Michel. A verdade e as formas jurídicas. Rio de Janeiro: editora Nau, 2005, pp. 7-27. 
JAPIASSU, Hilton. Introdução ao pensamento epistemológico. 5.ed. Rio de Janeiro, Francisco Alves, 1934, 202 p. (páginas 01 a 39).

JAPIASSU, Hilton. Interdisciplinaridade e patologia do saber. Rio de Janeiro, Imago, 1976, 220 p. (páginas 39 a 113).

KOPENAWA, Davi; ALBERT, Bruce. A queda do céu: Palavras de um xamã yanomami; trad. Beatriz Perrone-Moisés. São Paulo: Companhia das Letras, 2015, pp. 63-87;

KUHN, Thomas. A estrutura das revoluções científicas. Tradução Beatriz Vianna Boeira e Nelson Boeira. São Paulo: Perspectiva, 2013, p. 1-53; p. 132-186.

MIGNOLO, Walter. Desobediência epistêmica: a opção descolonial e o significado de identidade em política. Cadernos de Letras da UFF-Dossiê: Literatura, língua e identidade, v. 34, p. 287-324, 2008.

OLIVEIRA FILHO, José Jeremias de - "Reconstruções Metodológicas de Processos de Investigação Social" - Revista de História (FFLC H-USP), n. ${ }^{\circ}$ 107, vol. LIV, ano XXVII, jul.-set. 1976, páginas 263-276.

QUIJANO, Aníbal. Colonialidade do poder. A colonialidade do saber: eurocentrismo e ciências sociais. Perspectivas latino-americanas. Buenos Aires: CLACSO, 2005.

SANTOS, Boaventura de Sousa; MENESES, Maria Paula. Epistemologias do sul. In: Epistemologias do Sul. Cortez, 2010. (P. 23-72).

WALLERSTEIN, I. (1974a). O sistema mundial moderno. Vol. II: o mercantilismo e a consolidação da economia-mundo europeia, 1600-1750. Porto: Ed. Afrontamentos.

WALSH, C. Interculturalidade crítica e educação intercultural. 2009. (Conferência apresentada no Seminário "Interculturalidad y Educación Intercultural", Instituto Internacional de Integración del Convenio Andrés Bello, La Paz). Disponível em:https://docs.google.com/document/d/1OLHi_jHm12faZykJUO9nLlbsPKInOWn98T r14Gu8A4s/edit?copiedFromTrash. Acesso em: 12jun. 2019. 